\title{
Effects of 3 surface types on dairy cattle behavior, preference, and hygiene
}

\author{
K. E. Schütz, ${ }^{1 *}$ V. M. Cave,${ }^{1}$ N. R. Cox,${ }^{1}$ F. J. Huddart, ${ }^{1}$ and C. B. Tucker ${ }^{2}$ \\ ${ }^{1}$ AgResearch Ltd., Ruakura Research Centre, Hamilton 3214, New Zealand \\ ${ }^{2}$ Center for Animal Welfare, Department of Animal Science, University of California, 1 Shields Avenue, Davis 95616
}

\section{ABSTRACT}

Muddy surfaces have negative effects on the health and welfare of dairy cattle, and if possible, cows will avoid this surface. However, it is unclear whether it is the moisture content or the contamination with manure that is aversive to the cows. This study aimed to assess the use and preference for different wood chip (0.4 m deep) surface types: (1) clean and dry (clean, dry matter content, DM: $44 \pm 2.8 \%$ ), (2) dirty (dirty, contaminated with manure, DM: $40 \pm 3.7 \%$ ), and (3) clean and wet (wet, wetted by water, DM: $23 \pm 3.3 \%$ ). Eighteen nonlactating, pregnant cows were tested individually (mean 24 -h temperature: $9.9 \pm 4.46^{\circ} \mathrm{C}$, mean \pm standard deviation for all preceding values). Cows were kept indoors in test pens for $18 \mathrm{~h}$ on wood chip without feed and $6 \mathrm{~h}$ on pasture to allow for daily feed intake. To ensure cows made informed choices and to measure changes in behavior and hygiene associated with each option, they were first exposed to each surface for 5 d $(n=12$ cows per surface type when they were restricted on one surface; i.e., each cow was exposed to 2 treatment surfaces only). Cows on the wet surface spent the least amount of time lying when restricted to one surface for $18 \mathrm{~h}$ (wet: $21 \%$, dirty: $57 \%$, clean: $64 \%$ ) and spent more time lying when on pasture for $6 \mathrm{~h}$ (wet: $13 \%$, dirty: $4 \%$, clean: $3 \%$ ). The total lying times during the 5 -d surface exposure were wet: $4.6 \pm 1.04 \mathrm{~h}$, dirty: $10.6 \pm 0.25 \mathrm{~h}$, and clean: $11.7 \pm 0.25 \mathrm{~h}$ per $24 \mathrm{~h}$. Cows restricted on the wet surface for $18 \mathrm{~h}$ had fewer bouts (no.) of lateral lying (wet: $0.9 \pm 1.36$, dirty: $6.3 \pm$ 1.36, clean: $8.4 \pm 1.38$ ), spent less time lying with their heads supported (wet: $18.9 \pm 7.17 \mathrm{~min}$, dirty: $36.7 \pm$ $7.17 \mathrm{~min}$, clean: $39.1 \pm 7.26 \mathrm{~min}$ ), and spent less time with the front legs tucked (wet: $16 \pm 4.3 \%$, dirty: 41 $\pm 4.3 \%$, clean: $50 \pm 4.3 \%$ of time spent lying, mean \pm standard error of the mean for all preceding values), than cows on the other surfaces. Cows on the dirty sur-

Received March 21, 2018.

Accepted October 18, 2018.

*Corresponding author: karin.schutz@agresearch.co.nz face were less clean compared with the other treatment groups ( 0.6 of a score on a 5 -point scale; standard error of the differences of means: 0.11 for both comparisons). They were then given a free choice between 2 known surfaces for 2 consecutive days $(n=6$ per pairwise choice). Cows ranked the surfaces as clean $>$ dirty $>$ wet. In summary, there is compelling evidence that wet surfaces impair the welfare of dairy cattle by affecting the quantity and quality of rest. Rebound responses indicate that the motivation to rest is not fulfilled on wet surfaces. Finally, when given a choice, they show clearly that they will avoid wet and dirty surfaces. The combined results indicate that changes in affective state likely underlie these behavioral responses.

Key words: behavior, hygiene, lying, preference, surface type

\section{INTRODUCTION}

In pasture based dairy systems where cattle are predominantly managed outdoors all year, such as in New Zealand, they are sometimes taken off pasture to a separate area in periods of wet weather. This is done to protect the soil from treading damage and subsequent reduced pasture growth. Stand-off practices, including the total time away from pasture each day, vary between regions, but time away from pasture can be as high as 22 to $24 \mathrm{~h}$ for several consecutive days. Common surfaces that cattle are managed on during stand-off practices include concrete (at milking facility or on feed pads), race laneways, specially constructed wood chip pads, small "sacrifice" paddocks, and more recently, rubber matting on concrete. Research has shown that temporarily managing cattle on hard surfaces, such as concrete, has negative effects on the welfare of animals; cows have severely reduced lying times, lose BW, have impaired gait patterns (Fisher et al., 2003; Schütz and Cox, 2014), and have increased fecal glucocorticoid metabolites (Fisher et al., 2003).

Pastured dairy cattle spend between 10 and $12 \mathrm{~h}$ per day lying down, and similar lying times are achieved on a well-managed wood chip surface (Fisher et al., 2003; Schütz and Cox, 2014). Lying times and lying behavior has been used in numerous studies as a welfare indica- 
tor to distinguish different surface types (Fregonesi and Leaver, 2001; Fisher et al., 2003; Tucker et al., 2003; Schütz and Cox, 2014). Whereas it is well-known that dairy cattle avoid and spend less time lying on concrete surfaces, there is now also growing information that cows avoid lying down on wet (Fregonesi et al., 2007; Reich et al., 2010) and muddy surfaces (Fisher et al., 2003; Tucker et al., 2007; Chen et al., 2017). In a study simulating a 4-d stand-off period in New Zealand, nonlactating cows spent 41 and $47 \%$ less time lying when managed on a concrete or a muddy surface (small paddock and race laneway), respectively, compared with a well-drained wood chip surface (Fisher et al., 2003). Cattle with reduced lying times during the stand-off period will spend more time lying on pasture when they are allowed their daily feed allowance (Fisher et al., 2003; Schütz and Cox 2014; Schütz et al., 2015), a time where, ideally, they should be grazing. In addition, wet underfoot conditions are a contributing factor to softer hooves and therefore a greater risk for claw lesions and lameness (Williams et al., 1986; Jubb and Malmo, 1991; Borderas et al., 2004).

A well-drained and well-managed wood chip surface has been shown to provide dairy cattle with a comfortable lying area during stand-off periods; however, depending on stocking density and usage, these surfaces can become wet and muddy. The mud consists of a combination of wood chip, manure, urine, and rain water, as most stand-off surfaces are uncovered. Dairy cattle are able to distinguish between dirt that varies in DM content and avoid lying in mud (Chen et al., 2017); however, it is not known if it is the contamination of manure and urine or the wetness itself (e.g., by changed conductivity and thereby thermoregulation) that is aversive to cows. Therefore, the aim of this study was to investigate dairy cattle lying behavior on 3 types of deep-bedded wood chip surfaces: those that were clean, wet, or dirty (soiled with feces). We predicted that the quality and quantity of rest, locomotion, and hygiene would be impaired by wet and soiled surfaces, compared with a clean and dry control. We also predicted that when given a choice, cows would show clear, marked preferences for clean, dry lying surfaces over those that were either wet or soiled.

\section{MATERIALS AND METHODS}

\section{Animals and Study Design}

The study was undertaken at the Ruakura Research farm, AgResearch Ltd. in Hamilton between May and July 2015. All procedures involving animals were approved by the Ruakura Animal Ethics Committee under the New Zealand Animal Welfare Act 1999. The study used 18 nonlactating (16 pregnant, 2 nonpregnant) Friesian and Friesian-cross dairy cows that were between 5 and 8 yr of age, and with an average BW of $545 \pm 35.0 \mathrm{~kg}( \pm \mathrm{SD})$. A vaginal controlled internal drug release insert (Eazi-Breed CIDR, DEC Manufacturing, Hamilton, New Zealand) was inserted into the nonpregnant cows to prevent estrus behavior. The cows were divided into 3 treatment groups of 6 cows balanced by BW, but managed and tested in 2 blocks of 9 due to space restrictions in the experimental barn (9 available pens). The cows were tested individually in pens containing the different surface treatments. All cows were habituated to the individual pens containing dry, clean wood chip, for three 18-h periods, before the study. The 3 treatments (described below) were (1) clean, dry wood chip (clean), (2) clean, wet wood chip (wetted by water, wet), and (3) dirty wood chip (contaminated with manure, dirty).

The experimental design is presented in Table 1. Each cow was exposed to 2 no-choice phases in which the animal only had access to one surface type. The no-choice phases consisted of 5 consecutive 24-h periods, each consisting of $18 \mathrm{~h}$ restricted on one surface (overnight) and $6 \mathrm{~h}$ on pasture. The cows had $9 \mathrm{~d}$ (24 h) of recovery on pasture in between each surface exposure to minimize any carry-over effects. The order of exposure was balanced between cows. The 2 no-choice phases were followed by a choice phase where the cow had a free choice between the 2 treatments she had previously experienced. The choice phase lasted for 2 consecutive 18-h periods (over $48 \mathrm{~h}$ ) where the cow could move freely between the 2 surface types. Thus, each cow was exposed to 2 surface types (no-choice, $n$ $=12$ cows per surface type) before being given a free choice between the 2 known surfaces $(n=6$ cows/pairwise choice; Table 1).

During the no-choice and the choice phases, the cows were in the treatment pens between 1500 and $0900 \mathrm{~h}$ the following day, simulating a typical New Zealand stand-off practice. The remaining time $(6 \mathrm{~h})$ was spent on pasture as a block of 9 cows, to allow for their daily feed intake (a fresh sward of pasture and grass silage supplement with a total ration of approximately $11 \mathrm{~kg}$ of DM per cow and day). The treatment surfaces were cleaned and restored daily as near as possible to their original condition while the cows were at pasture. In addition, treatment surfaces were fully replaced between testing of the 2 blocks. The cows had access to water provided ad libitum in a bucket that was refilled daily. Each cow was also given a small amount (handful) of hay every day to encourage them to enter; otherwise, no feed was available in the treatment pens. The aver- 
age outside 24-h temperature during testing was 9.9 $\pm 4.46^{\circ} \mathrm{C}( \pm \mathrm{SD})$ measured using a portable weather station recording every $10 \mathrm{~min}$ (Vantage Pro2 Plus, Davis Instruments Corp., Hayward, CA) located in an unsheltered location outside the facility.

\section{Experimental Facility and Treatments}

The experimental facility consisted of a barn measuring $19 \times 7.9 \mathrm{~m}$ with a solid roof and with sides that were either solid or covered with plywood, wind break, and clear light plastic sheeting to minimize the effects of weather but allow sufficient ventilation. Nine pens were constructed within the facility, each consisting of 2 boxes (length: $3 \mathrm{~m}$, width: $2.2 \mathrm{~m}$, height: $0.41 \mathrm{~m}$, constructed from 20-mm-thick plywood, Figure 1). The boxes were placed long side by long side in a row and held in place by attaching them to existing timber rails. A portable interlocking yard system (Prattley gates, Prattley Industries Ltd., Temuka, New Zealand), were used as gates and to provide divisions between pens. Plywood was attached to the gates between the pens to prevent tactile contact between cows; however, the cows could see other cows across the laneway as pens were located opposite each other ( 5 on one side, 4 on the other). The central laneway between the 2 rows of pens was $0.2 \mathrm{~m}$ of deep wood chip on a concrete base. The wood chip was added to provide a more comfortable walking surface as well as lessen the step to the pens (Figure 1).

To create the treatments, each plywood box was filled with approximately $2.1 \mathrm{~m}^{3}$ of wood-chipper fines (a by-product from the milling process of exportquality Pinus radiata, with a particle size such that it has passed through a $10 \times 10 \mathrm{~mm}$ steel mesh screen, Mooreys Contracting Ltd., Matamata, New Zealand). This amount of wood chip resulted in the boxes being filled level with the plywood edges and slightly raised in the center, giving the cow easy access to both beds and allowing for some consolidation of the wood chip. Thus, the whole pen consisted of the 2 boxes filled with wood chip (Figure 1). The 3 surface treatments (Figure 2) were (1) clean: clean and dry wood chip. The boxes were filled with fresh wood chip and levelled. (2) wet: wet wood chip. The beds were filled with fresh wood chip and levelled. Water was then sprayed over the surface through a K24 electronic turbine meterpulser (Piusi S.p.a, Suzzara, Mantova, Italy); 1,000 L was initially applied and left overnight. The following day more water was gradually applied until the water table was approximately 1 to $2 \mathrm{~cm}$ below the surface and "treading" on the bed brought the water to the surface. (3) dirty: dirty wood chip. The beds were filled with fresh wood chip and levelled. Soiled wood chip and manure that had been removed during previous cleaning was thoroughly mixed to a ratio of approximately $60 \%$ manure and $40 \%$ wood chip (by eye). This was then placed and compacted in a bucket (approximately $8 \mathrm{~L}$ ) and applied in a grid pattern on the bed (Figure 2) consistent for all the pens with the dirty surface.

During the no-choice phase each cow was presented with 2 beds containing the same surface type (total area of $13.2 \mathrm{~m}^{2}$ ). During the choice phase each cow was presented with one bed each of the treatments they had previously experienced $\left(6.6 \mathrm{~m}^{2}\right.$ area per treatment). During the choice phase, the wood chip was levelled between the bedding boxes so that the wooden lip between the 2 boxes gently encouraged the cows not to lie down on both beds.

\section{Surface Measures}

Surface temperature was assessed using infrared thermography (IRT) and a handheld IRT camera

Table 1. Experimental design where dairy cattle behavioral responses to surfaces that were clean, wet, or dirty were tested ${ }^{1}$

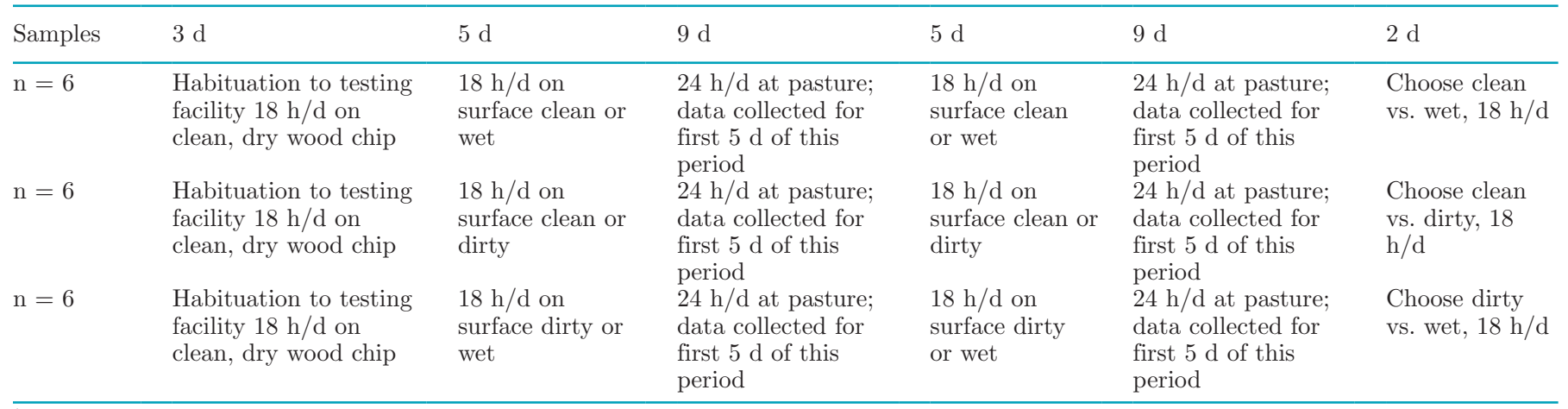

${ }^{1}$ The initial phase of the experiment exposed cattle to each surface exclusively with periods of habituation or rest beforehand. In the final phase, cattle were asked to choose between 2 surfaces. 


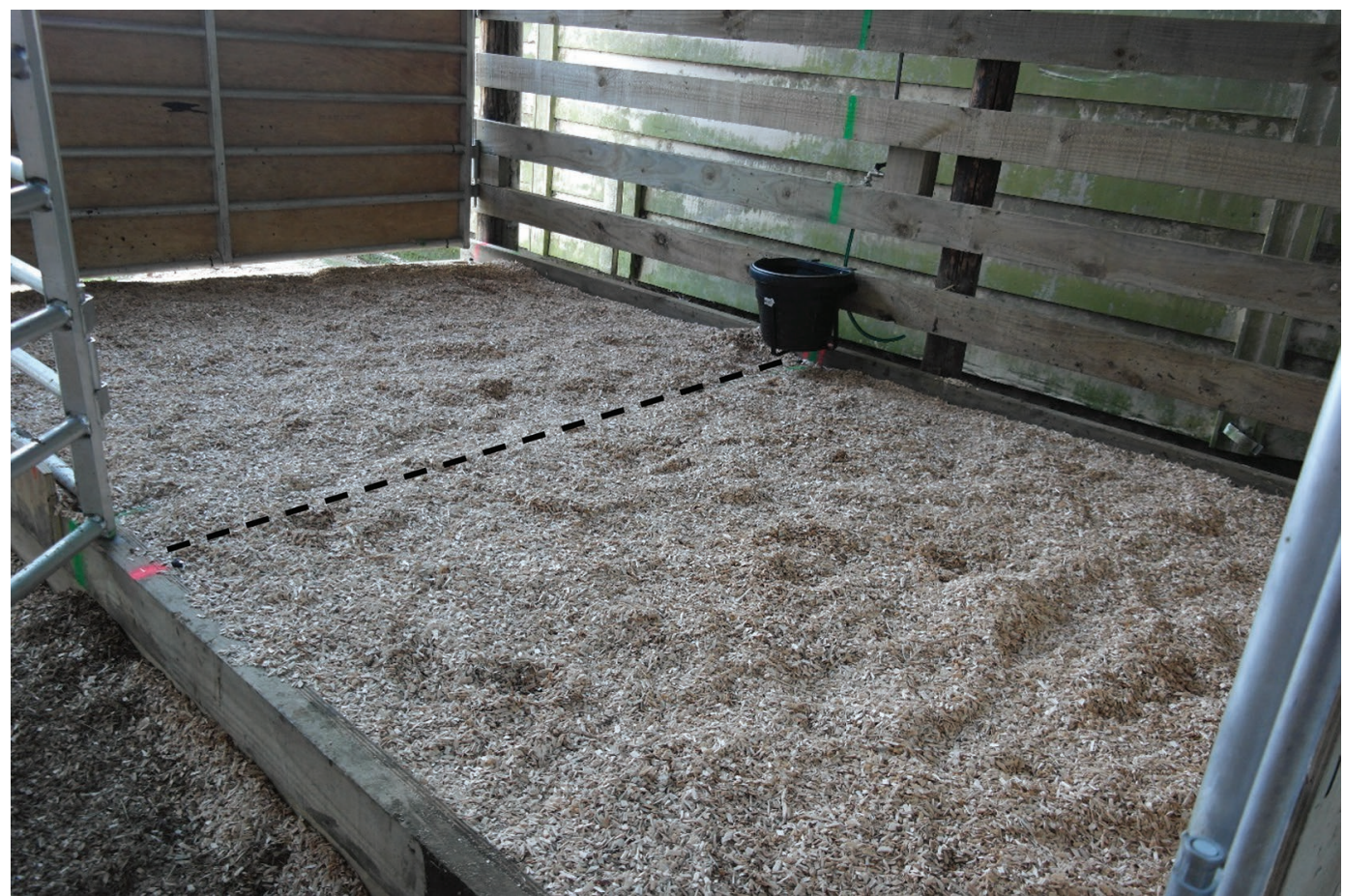

Figure 1. The clean treatment pen consisted of 2 plywood boxes, filled with wood chip, and separated by the indicated dashed line.

(ThermaCAM S60, FLIR Systems AB, Danderyd, Sweden). The camera was calibrated for temperature, relative humidity, and emissivity. Images that covered the whole surface were collected for each wood chip box (2 per pen). Images were then analyzed using FLIR Researcher software (version 2.10) to calculate the average surface temperature for each pen.

To measure the DM content of the treatments, 3 pooled samples per box were collected each morning before cleaning the pens. Each sample consisted of 3 samples from the front, middle, and back of the box, respectively. In addition, the DM content of the applied manure in the dirty treatment was measured by taking samples before application on the surface. The samples were dried for $48 \mathrm{~h}$ at $65^{\circ} \mathrm{C}$ and the percentage $\mathrm{DM}$ content calculated as dry weight/wet weight $\times 100$.

\section{Animal Measures}

Lying and standing times were recorded continuously using Onset Pendant G data loggers (64k, Onset Computer Corporation, Bourne, MA) set to record the $\mathrm{y}$ - and z-axes at a 30-s interval. The data loggers were placed in a durable fabric pouch and attached on the lateral side of the hind leg above the metatarsophalangeal joint. The pouch was held in position by Velcro patches, one sewn to the pouch, the other glued (Kamar Adhesive, Kamar Products Inc., Zionsville,

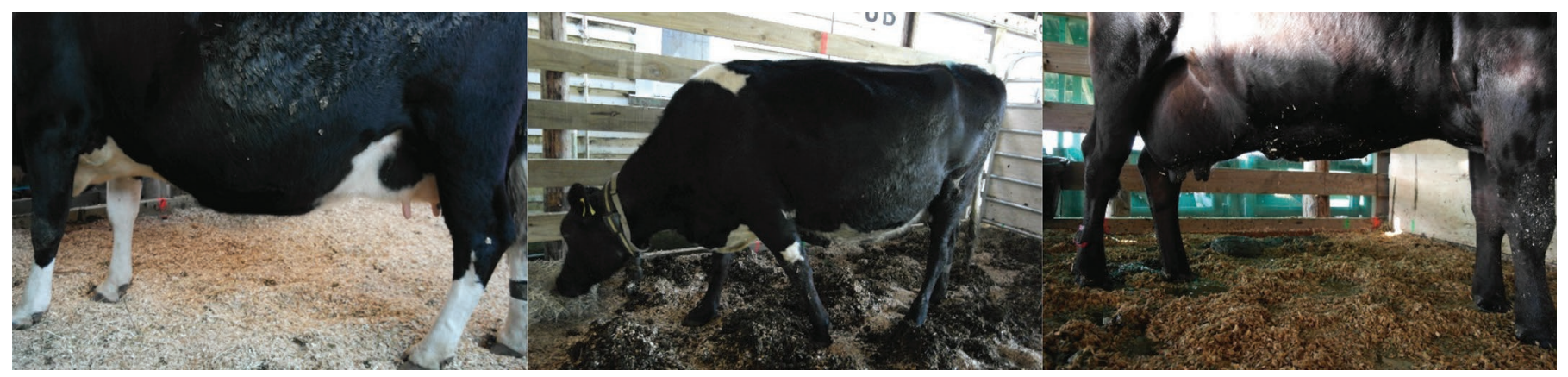

Figure 2. Cows in the different treatments: clean, dirty, and wet wood chip. 
IN) to the leg of the cow. The pouch was further held in place by a strap around the leg of the cow. The data were downloaded using HOBOware Pro software (Onset Corp., Pocasset, MA) and daily summaries of lying behavior (total lying time and bout information (number of bouts and bout duration) calculated using raw data in Excel (Microsoft Corp., Redmond, WA), correcting for single events.

The behavior of cows during the no-choice phase, and the location and behavior of cows during the choice phase was observed from video recordings. A WSS CCTV system (Waikato Security Services, Hamilton, New Zealand) was installed using a Hikvision 2 Series $3 \mathrm{MP}$ full HD fixed lens with EXIR turret camera (DS2CD2332-I, Hikvision, Hangzhou, China) per pen for continuous recording of behavior. The cameras built-in infrared light enabled night recordings. Video footage was analyzed using Adobe Premiere Pro CC (Version 8.1, Caravan, Adobe Systems Software Ltd., San Jose, CA). Observations from video recordings were undertaken between 1530 and $0830 \mathrm{~h}$. During the no-choice phase, we observed the behavior of $\mathrm{d} 1$ and 5 , which are presented in Table 2. Three observers recorded lying behavior and head position. Average inter-observer reliability for lying position was $80 \%$ and for head position $71 \%$, measured as percentage agreement. One person observed weight shifting, leg position, and rumination. Intra-observer reliability for these behaviors ranged between 97 and $100 \%$, measured as percentage agreement. The reliability was lowest when measuring rumination.

During the free choice phase, the location of each cow was observed continuously for $17 \mathrm{~h}$ (between 1530 and $0830 \mathrm{~h}$ ) from the video recordings. A cow was considered to be on a surface when she had at least 3 hooves in one of the treatment boxes (Figure 2). If she stood with 2 hooves on each treatment surface for more than $5 \mathrm{~s}$ this was also recorded. In addition, it was recorded whether the cows was lying (defined as no BW supported by any leg) or standing (not lying). Finally, the times and location of defecation and urination were also recorded when animals were lying or standing.

As a measure of the risk for lameness, gait score was recorded on a 5 -point scale (Table 3 ) before and after each no-choice treatment period ( $5 \mathrm{~d}$ ) as cows entered and left the experimental facility. One trained person recorded all gait scores. Each cow was given a hygiene score twice daily, before entering their pens in the afternoon and before leaving the pens the following morning using a 5-point scale on 8 areas of the body: left and right flank, left and right upper rear limbs, lower rear limbs, ventral abdomen, and tail. The scoring was 1: no evidence of manure contamination, 2: some splashing, 3: some clumps, 4: moderate clumps, and 5: a considerable number of manure clumps. The scores were averaged to calculate an overall hygiene score for every animal on each bedding. Inter-observer reliability (2 observers) for the hygiene scoring ranged between 67 and $94 \%$ as measured as percentage agreement. The inter-observer reliability was lowest when measuring the udder (one score was measured for the whole udder, and the measure was very variable depending on where the observer was standing).

\section{Statistical Analysis}

Each cow was the observational unit $(\mathrm{n}=18)$. Lying behavior during the no-choice phase was analyzed using REML with animal within group by period random terms to reflect the blocking structure and changeover design, and treatment as the fixed term. To address

Table 2. Definitions of behavior recorded during the no-choice phase

\begin{tabular}{|c|c|}
\hline Behavior & Definition \\
\hline Sternal lying ${ }^{1}$ & $\begin{array}{l}\text { The weight of the cow is on the sternum. A bout ended when the cow changed position (to/from standing } \\
\text { or from lateral lying). }\end{array}$ \\
\hline Lateral lying $^{1}$ & $\begin{array}{l}\text { The weight of the cow is on one side of the body including the shoulder, barrel, and hip. A bout ended } \\
\text { when the cow moved into sternal position or was standing up (standing was defined as when the BW was } \\
\text { supported by any leg). }\end{array}$ \\
\hline \multicolumn{2}{|r|}{ 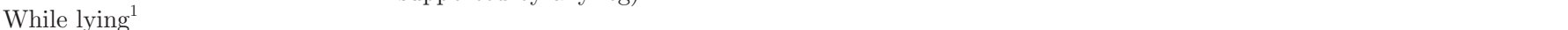 } \\
\hline Head unsupported & The head is unsupported. \\
\hline Head supported on body & The head is resting on the body, excluding grooming. \\
\hline Head supported on ground & Any part of the head resting on the ground. \\
\hline None of the above & The head is not visible. \\
\hline Front legs tucked & One or both front legs are bent. \\
\hline Font legs nontucked & One or both front legs are extended. \\
\hline Exposed hind leg tucked & Visible hind leg is parallel or closer to the body. \\
\hline Exposed hind leg extended & Visible hind leg is not tucked. \\
\hline Ruminating $^{2}$ & Chewing movements without fresh feed being ingested. \\
\hline Weight shifting ${ }^{2}$ & Body weight is shifted between hind legs while being stationary. \\
\hline
\end{tabular}

${ }^{1}$ Continuous observations.

${ }^{2} 30$-s scan observations (each time the cow was watched for $5 \mathrm{~s}$ ). 
treatment-specific heterogeneity of variance, the analyses allowed for a larger residual variation in the wet treatment. Random terms for previous treatment and the interaction of this with current treatment were included initially to check for carry-over effects; for the first phase, the previous treatment for animals was the clean treatment. With the lack of evidence for such carry-over effects, the terms for these were subsequently dropped from the analyses. Lying time, percentage of time lying, the number of lying bouts, and the average lying bout length was analyzed for the time on the surface $(18 \mathrm{~h})$, the time on pasture $(6 \mathrm{~h})$, the total time on surface and pasture, and the time on pasture during recovery $(5 \mathrm{~d})$. Pair-wise comparisons were made using $t$-tests based on the means, standard errors, and degrees of freedom from the REML analyses. Overall hygiene score was analyzed using paired $t$-tests.

To investigate changes in behavior within a no-choice period (1st and last 18-h period within one surface exposure), the behavior (bouts and duration of sternal and lateral lying, head supported and unsupported, and the proportion of time per day ruminating, lying with a front leg tucked, and lying with a hind leg tucked) of the cows during the no-choice phase was also analyzed using REML with treatment as the fixed term. Random terms of animal within group by day within period were used to account for the blocking structure and the changeover design comprising 2 measurements per period (on d 1 and 5 of treatment exposure).

For all REML analyzes, random terms were constrained to be positive. Unprotected Fisher's least significant differences at the $5 \%$ level were used to compare treatment means. Where $P$-values are provided, these were calculated from $t$-tests using the standard errors from the REML analysis.

All preference data (proportion of time on each surface, lying or standing, and rate of defecation and urination per hour on each surface) from the free choice phase were analyzed using paired $t$-tests.

All statistical analyses were conducted using the statistical package Genstat, version 17 (VSN International, Hemel Hempstead, UK). Due to low gait scores and too infrequent recording of weight shifting behavior, these variables were not statistically analyzed.

\section{RESULTS}

\section{Surface Measures}

Due to equipment malfunction, the majority $(73 \%)$ of IRT data were lost and therefore could not be analyzed. However, based on the limited data available, the average surface temperature was, for clean: $13 \pm$ $2.7^{\circ} \mathrm{C}$, dirty: $14 \pm 3.3^{\circ} \mathrm{C}$, and wet: $12 \pm 3.1^{\circ} \mathrm{C}$ (mean \pm $\mathrm{SD})$. The DM content for clean, dirty, and wet was 45 $\pm 2.2 \%, 40 \pm 3.5 \%$, and $23 \pm 3.2 \%$, respectively (mean $\pm \mathrm{SD})$. The DM content of the applied manure in the dirty treatment was, on average, $24 \%$ (SD: 1.4\%).

\section{Animal Measures}

No-Choice Phase. When cows had access to only one treatment between 1500 and $0900 \mathrm{~h}(18 \mathrm{~h})$, they spent the least amount of time lying on the wet surface and most on the clean (Figure 3). Cows only spent about one-third of the time lying on the wet wood chip compared with the other surface types. When the cows were on pasture for $6 \mathrm{~h}$ to allow for their daily feed intake, cows that had been on the wet surface spent more time lying (Figure 3). Even though cows on the wet surface spent more time lying on pasture, their total lying times over $24 \mathrm{~h}$ (treatment and pasture combined) were significantly lower compared with the cows on the other surface types (Figure 3). Also, cows that were on the dirty surface had lower total lying times compared with cows on clean surface (Figure 3 ); the total lying times during the 5-d treatment exposure was, on average, for wet: $4.6 \pm 0.80 \mathrm{~h}$, dirty: $10.5 \pm 0.27 \mathrm{~h}$, and clean: $11.7 \pm 0.27 \mathrm{~h}$ (mean $\pm \mathrm{SEM})$. The $t$-ratios for dirty versus clean $(P=0.008)$, dirty versus wet $(P<$ $0.001)$, and clean versus wet $(P<0.001)$ were 3.07 , 6.94 , and 8.33, respectively, with 14 degrees of freedom.

Lying bout information is presented in Table 4. Cows on the wet treatment had fewer lying bouts when on the surface but no difference was observed in the average length of the lying bouts between wet and the other treatments. Cows exposed to the wet surface also had more frequent and longer lying bouts than the other 2 treatments when on their 6 -h pasture break. In total, cows on the wet surface had fewer lying bouts than

Table 3. Gait score used in the study (Thomsen et al., 2008)

\begin{tabular}{ll}
\hline Gait score & Definition \\
\hline 1 & Walks normally. Hooves are placed with confidence, rear hooves placed where front hooves were. \\
2 & Gait is slightly abnormal. Back is arched while walking. Head is held lower and extended from the body. \\
3 & The back is arched both when standing and walking. Short steps with one or more legs. \\
4 & Back is arched both when standing and when walking. Tries to reduce the weight on one or more hooves. \\
5 & Pronounced arching of back. Reluctant to move, with almost complete weight transfer off affected limb. \\
\hline
\end{tabular}


Table 4. Average number of lying bouts (per day) and average bout length ( \pm SEM) of nonlactating, pregnant dairy cows when exposed to 1 of 3 surface types (clean, dirty, or wet deep-bedded wood chip) for $18 \mathrm{~h} / 24 \mathrm{~h}$ for 5 consecutive days between 1500 and $0900 \mathrm{~h}$ (n $=12 \mathrm{per}$ surface type $)^{1}$

\begin{tabular}{|c|c|c|c|c|c|}
\hline Item & Wet & Dirty & Clean & Test statistic & $P$-value \\
\hline
\end{tabular}

${ }^{\mathrm{a}-\mathrm{c}}$ Different letters within a row indicate $P \leq 0.05$ based on pair-wise comparisons.

${ }^{1}$ The values are averages for when the animals were on each surface type $(18 \mathrm{~h})$, on $6 \mathrm{~h}$ on pasture in between surface exposures (0900 to 1500 $\mathrm{h})$, and combined over $24 \mathrm{~h}$. Test statistic and overall $P$-values are presented.

the other 2 treatments. Cows on the clean surface had the highest number of lying bouts than the other 2 treatments; however, the bout length was shorter than the cows on the dirty surface. The bout frequency and duration of the cows exposed to the clean surface was similar to those of cows on the dirty treatment when on their 6-h pasture break. In total, cows on the clean surface had the greatest number of lying bouts, but of shorter duration than those of cows on the dirty surface.

Time spent lying during the no-choice phase in a sternal or lateral position, and with the head supported or unsupported for the different treatments is presented in Table 5. Cows in the wet treatment spent less time lying in a sternal position and had fewer bouts in this position and fewer bouts of lateral lying compared with the other treatments $(P<0.05)$. In addition, cows on the dirty surface had fewer lying bouts (sternal lying) than cows on the clean surface $(P<0.05)$. Cows on the wet treatment spent less time lying with the head supported and unsupported and had fewer bouts of these behaviors than the other treatments $(P<0.05)$. Head position could not always be observed, for example, when the animal was facing away from the camera. The percentage of times the head position of a cow was missing over the $4 \mathrm{~d}$ of recording (2 per surface

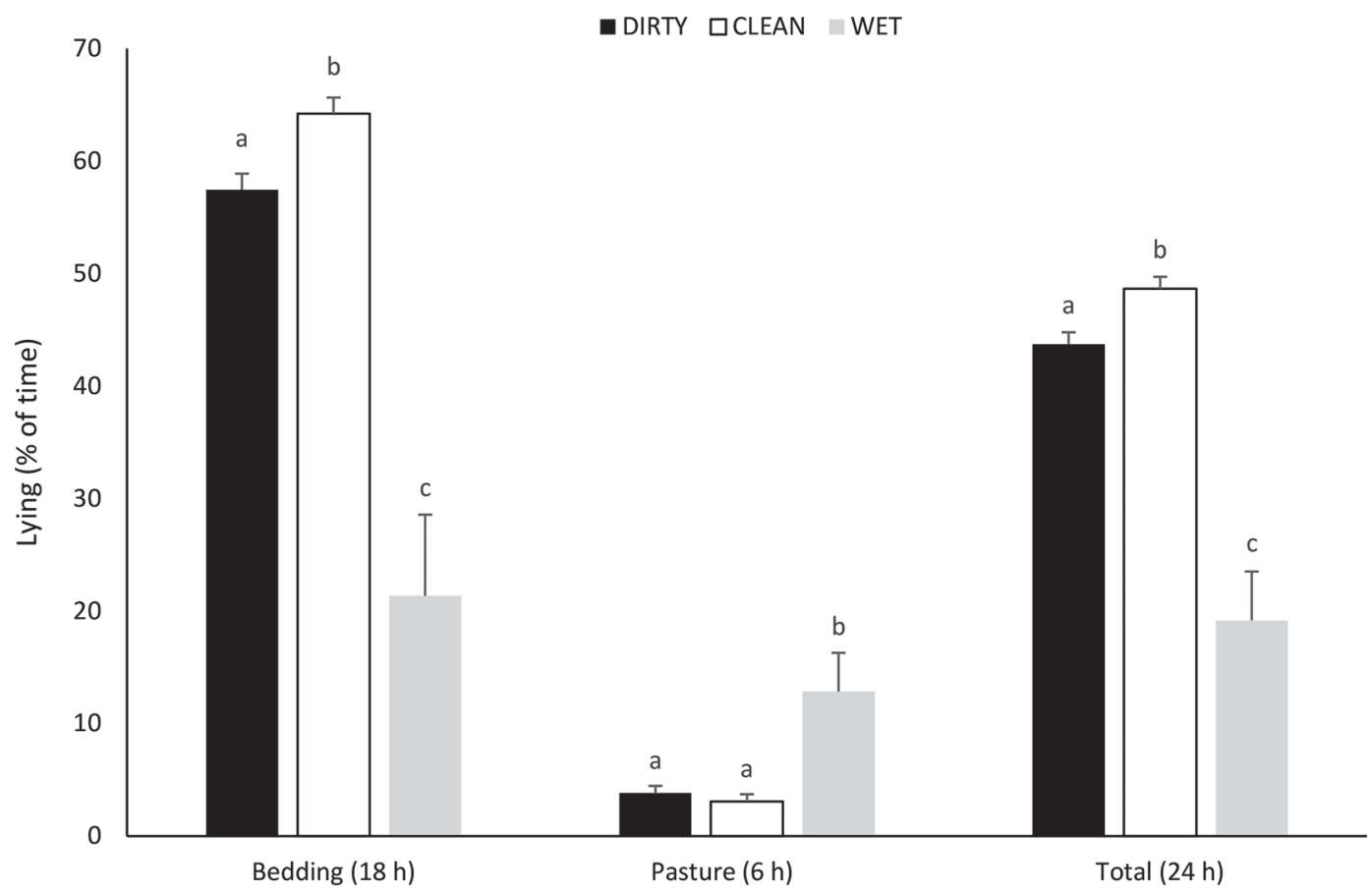

Figure 3. Lying times (\% of time) of nonlactating, pregnant dairy cattle exposed to 1 of 3 surface types (clean, dirty, or wet wood chip) for $18 \mathrm{~h}$ per day for 5 consecutive days between 1500 and $0900 \mathrm{~h}(\mathrm{n}=12$ per surface type). Values are mean lying times and SEM of total time on 1 surface type $(18 \mathrm{~h}), 6 \mathrm{~h}$ on pasture in between treatment exposures (0900 to $1500 \mathrm{~h}$ ), and total lying times (24 h). Different letters [a-c within surface $(18 \mathrm{~h})$, pasture $(6 \mathrm{~h})$, and total $(24 \mathrm{~h})]$ indicate $P<0.05$ (from $t$-tests with $14 \mathrm{df}$ ). 
Table 5. Time and number of bouts nonlactating, pregnant dairy cattle spent lying in a sternal or lateral position, and with the head supported or unsupported when exposed to 1 of 3 surface types for $18 \mathrm{~h} / 24 \mathrm{~h}$ for 5 consecutive days between 1500 and $0900 \mathrm{~h}(\mathrm{n}=12 \text { per surface type })^{1}$

\begin{tabular}{|c|c|c|c|c|c|}
\hline Item & Wet & Dirty & Clean & Test statistic & $P$-value \\
\hline Sternal lying (no.) & $3.6^{\mathrm{c}}( \pm 1.68)$ & $12.9^{\mathrm{a}}( \pm 1.68$ & $17.2^{\mathrm{b}}( \pm 1.70)$ & $F_{(2,19)}=28.87$ & $<0.001$ \\
\hline Head supported (min) & $18.9^{\mathrm{b}}( \pm 7.17)$ & $36.7^{\mathrm{a}}( \pm 7.17)$ & $39.1^{\mathrm{a}}( \pm 7.26)$ & $F_{(2,21)}=3.56$ & 0.047 \\
\hline Head supported (no.) & $3.3^{\mathrm{b}}( \pm 1.63)$ & $8.8^{\mathrm{a}}( \pm 1.63)$ & $10.1^{\mathrm{a}}( \pm 1.65)$ & $F_{(2,20)}=9.46$ & 0.001 \\
\hline Head unsupported (min) & $209^{\mathrm{b}}( \pm 37.3)$ & $515^{\mathrm{a}}( \pm 37.3)$ & $584^{\mathrm{a}}( \pm 37.7)$ & $F_{(2,25)}=33.79$ & $<0.001$ \\
\hline
\end{tabular}

${ }^{\mathrm{a}-\mathrm{c}}$ Different letters within a row indicate $P<0.05$.

${ }^{1}$ Surfaces were clean, dirty, or wet deep-bedded wood chip. Values are means and SEM for d 1 and 5 of exposure. Test statistic and overall $P$-values are presented.

type) was for dirty: $18 \%$ (range: 5 to $33 \%$ ), clean: $20 \%$ (range: 7 to $31 \%$ ), and wet: $15 \%$ (range: 0 to $39 \%$ ).

When the cows were lying there was a significant treatment effect for the time spent with 1 or 2 front legs tucked $\left(F_{2,30}=22.12, P<0.001\right)$. The cows on the wet surface spent less time in this position compared with the other treatments (wet: $16 \%$ of time spent lying \pm 4.3 , dirty: $41 \%$ of time spent lying \pm 4.3 , clean: $50 \%$ of time spent lying \pm 4.3 , mean \pm SEM). There was no treatment differences in the time spent lying with the exposed hind leg tucked against the body $\left(F_{2,30}=\right.$ 2.16, $P=0.133)$, or in the time spent ruminating in the pens $\left(F_{2,21}=1.07, P=0.360\right)$. When the cows were standing, the number of weight shifting between the hind legs was too infrequent to analyze; however, the behavior was seen in $0.6 \%$ (SD: 0.86) of observations in the wet treatment, whereas it was only observed in the other 2 treatments in $0.1 \%$ (SD: 0.28 ) of the observations.

No cows had a gait score greater than 2 on a 5 -point scale during the duration of the trial; however, 3 cows had an increase in gait score in both no-choice periods. Six of 12 cows in the wet treatment had an increase in gait score from 1 to 2 . This number was 5 out of 12 cows for cows in the clean treatment (from 1 to 2 ) and 2 of 12 for cows in the dirty treatment (no statistical analysis was undertaken). Cows were dirtier in the dirty treatment compared with the clean $\left(0.6\right.$ of a score, $\mathrm{t}_{5}$ $=5.62, P=0.002)$ and the wet treatments $(0.7$ of a score, $\left.\mathrm{t}_{5}=3.33, P=0.021\right)$. There was no difference in hygiene score between cows in the clean and wet treatments $\left(\mathrm{t}_{5}=0.10, P=0.196\right)$.

During the recovery phase on pasture after the 5 -d no-choice treatment exposure (first $5 \mathrm{~d}$ of 9 analyzed) there was an overall effect of treatment on lying time $\left(F_{2,18}=19.51, P<0.001\right)$ but not on the number of bouts $\left(F_{2,17}=1.68, P=0.217\right)$ or average bout length $\left(F_{2,15}=0.95, P=0.408\right)$. Cows in the wet treatment spent more time lying compared with cows on the clean $\left(\mathrm{t}_{18}=5.75, P<0.001\right)$ and dirty surfaces $\left(\mathrm{t}_{18}=4.99\right.$, $P<0.001)$; lying times were, on average, for wet: 12.1 h/24 h, dirty: $10.9 \mathrm{~h} / 24 \mathrm{~h}$, clean: $10.7 \mathrm{~h} / 24 \mathrm{~h}$ (SEM: 0.17 ). The daily lying times for all cows during the recovery phase is presented in Figure 4. The difference between the treatments was particularly marked on the first day after treatment exposure; however, differences were evident over the whole 5-d recovery period.

Free Choice Phase. When cows had a free pairwise choice between the treatments, they showed a clear preference for the clean surface; $98 \%$ of the time was spent on this surface versus the dirty surface and also versus the wet surface (Figure 5). When the cows had a choice between dirty and wet, cows preferred dirty; $94 \%$ of the time was spent on this surface (Figure $5)$. When the cows were on the preferred surface, the majority of the time was spent lying; 73 and $63 \%$ of the time was spent lying on the clean and dirty surfaces, respectively, compared with when the other option was wet. Similarly, when cows chose clean over dirty, they spent $73 \%$ of time lying on the clean surface.

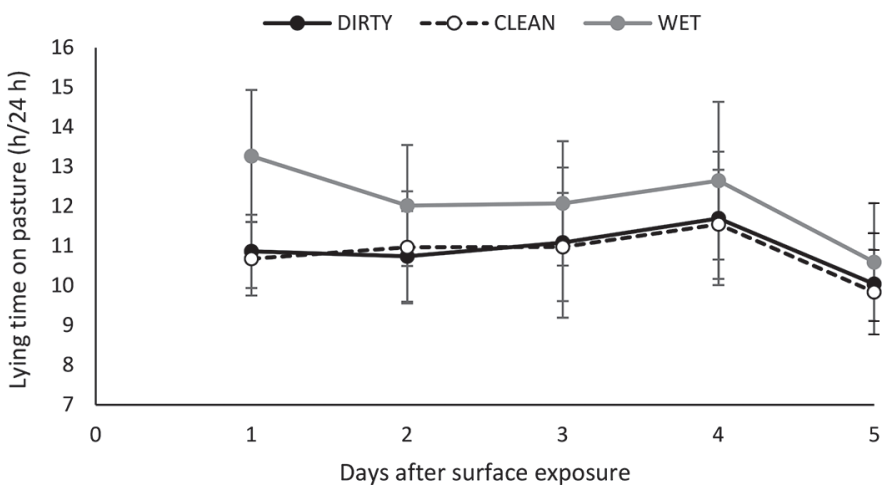

Figure 4. Daily lying times of nonlactating, pregnant dairy cattle when on pasture $(24 \mathrm{~h})$ after exposure to 1 of 3 surface types (clean, dirty, or wet wood chip) for $18 \mathrm{~h}$ per day with $6 \mathrm{~h}$ of daily pasture access, for 5 consecutive days $(\mathrm{n}=12$ per surface type). The values are means and SD. 


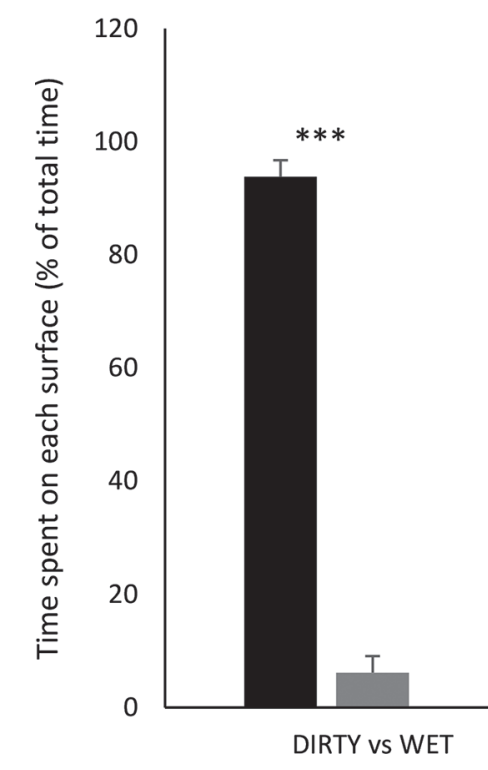

-DIRTY —WET DCLEAN

Figure 5. Total time spent on different surface types (clean, dirty, or wet) when given a free pair-wise presented choice between the different surfaces (\% time on each surface type of total time, $18 \mathrm{~h}$ per day for $2 \mathrm{~d}$ and SEM) of nonlactating, pregnant dairy cows ( $\mathrm{n}=6 \mathrm{cows}$ per pairwise choice). ${ }^{* * *} P<0.001$ (from paired $t$-tests with $5 \mathrm{df}$ ).

Cows did not show a statistically significant preference (rate of elimination) on which surface to urinate $(P \geq 0.053,5 \mathrm{df})$ or defecate $(P \geq 0.124,5 \mathrm{df})$; however cows had a tendency to avoid urinating on the clean surface (for clean $0.1 \pm 1.6$ urinations/h vs. dirty $4.1 \pm 1.6$ urinations $/ \mathrm{h}, P=0.053$; for clean $0.1 \pm 8.3$ urinations/h vs. wet $21.6 \pm 8.3$ urinations $/ \mathrm{h}, P=0.061$; mean $\pm \mathrm{SEM})$. There was no difference in urination between the dirty versus wet treatment $(P=0.273)$.

\section{DISCUSSION}

There is compelling evidence that wet surfaces impair the welfare of dairy cattle. Cattle reduce their lying time to biologically relevant low levels in response to wet surfaces. The quality of their rest while on a wet surface is also likely affected, as they engage in less time in postures associated with sleep. They show rebound behavior when given access to a better lying surface, both daily and after treatment ended, likely resulting in reduced opportunities to feed in order to lie down. Both of these responses indicate that their motivation to rest is not fulfilled on wet surfaces. Finally, when given a choice, they clearly avoid wet and dirty surfaces. The combined results indicate that changes in affective state likely underlie the behavioral responses.

Cows that are managed predominantly outdoors are exposed to ambient weather conditions, and muddy surfaces may be common in wet weather. Wet and muddy surfaces have several negative effects on the welfare of cattle. Research have shown a reduction in lying times on muddy surfaces in the magnitude of a 50 to $75 \%$ reduction compared with dry surfaces (Muller et al., 1996; Fisher et al., 2003; Chen et al., 2017), which is similar to that observed in the current study when cows were on the wet surfaces compared with the clean, dry surface (67\% reduction in lying time). The reduction in lying times when cows were on the surface contaminated with manure compared with the dry, clean surface ( $11 \%$ reduction in lying time) was smaller than that of cows on the wet treatment and suggests that the reduction in lying time is predominantly due to the moisture content of the surface. Lying time is an important welfare indicator in cattle (Haley et al., 2000) and severe reductions in lying times such as those reported here likely result in chronic stress (e.g., Munksgaard and Simonsen, 1996; Munksgaard et al., 1999; Fisher et al., 2002). In addition, walking and lying in mud increase energy requirements (Degen and Young, 1993; Tucker et al., 2007) and this is likely exacerbated in cold weather due to heat convection and animals losing heat to the environment (Morrison et al., 1970; Holmes et al., 1978). For example, simulated rain alone, or in combination with wind, decreased skin temperature by $26 \%$ on average (Schütz et al., 2010).

When the cows were kept on the wet surface they spent less time lying in a lateral position and with their heads supported either on the body or on the ground. Having the head supported is an important part of the quality of sleep, as rapid eye movement 
sleep only occurs when the head is supported (Ternman et al., 2014). Cattle on pasture were observed lying in a lateral position with their heads supported more than cows in a deep-bedded loose housing system (Krohn and Munksgaard 1993). Our results suggest that the wet surface was less comfortable and provided cows with fewer opportunities for quality sleep. This is also supported by the evidence that cows on the wet surface were observed shifting their weight between their hind legs more than cows on the other surfaces (numerical difference only). Weight shifting between the hind legs is commonly observed in cows deprived of lying (e.g., Cooper et al., 2007) and is suggested to aid in the alleviation of muscle tiredness associated with exacerbated standing (Rajapaksha and Tucker, 2014).

Cows that were on the wet surface showed clear compensatory lying behavior when they were on pasture, both after the daily exposure and after the 5-d treatment period, thus indicating that even a short-term reduction in lying time will alter the motivation for lying for several days. The same pattern of rebound behavior has been seen in other studies where dairy cattle are temporarily managed on hard and muddy surfaces (Fisher et al., 2003; Schütz and Cox, 2014), on rubber matting at high stocking densities (Schütz et al., 2015), and after periods of deprivation (Tucker et al., 2018). The collected evidence suggests that cows will give up feeding to compensate for previous, inadequate rest on uncomfortable or otherwise unsuitable conditions.

Despite the reduced lying times on the wet surface, there was no indication that the treatments caused an increased risk of developing lameness in terms of measured gait score; however, the length of exposure was likely too short to detect any changes in healthy animals without prior hoof or leg problems. In addition, we speculate that the periodic pasture exposure in between surface exposures facilitated movement and therefore reduced the potential discomfort caused by the treatments. Indeed, access to pasture has been shown to improve hoof health and lameness in indoor systems (Loberg et al., 2004; Hernandez-Mendo et al., 2007), possibly due to a combination of exercise and walking on a soft surface. However, changes in gait pattern (stride length and gait score) have previously been demonstrated under similar exposure to a concrete surface $(18 \mathrm{~h}$ on concrete/ $6 \mathrm{~h}$ on pasture for 4 consecutive days; Schütz and Cox, 2014), thus showing that cows may change their walking patterns after a relative short exposure to an uncomfortable surface.

Our results agree with previous research showing that cows spend more time lying on dry surfaces, both in a pasture-based dairy system (Fisher et al., 2003) and in freestall systems (Fregonesi et al., 2007; Reich et al., 2010), and when given a free choice, cows prefer dry bedding over wet bedding (freestalls: Fregonesi et al., 2007; Reich et al., 2010). Cattle will even chose to lie on concrete over wet and muddy surfaces (Chen et al., 2017). Our results show that cows on a wet surface will reduce their lying time to levels that is likely to cause issues, such as chronic stress and lameness, if the exposure is long-term. The quality of their rest while on wet surfaces is also likely affected, as they engage in less time in postures associated with sleep. Also, they show rebound behavior when given access to a pasture surface after being on a wet surface. Finally, when given a choice, they show clear preferences that they will avoid wet and dirty surfaces. These last 2 findings, in particular, indicate that changes in affective state likely underlie the observed behavioral responses.

Wet surfaces may be aversive to cows for several biological reasons. First, in cold conditions, lying on a wet surface will increase heat loss due to convection to the colder surface, and may lead to issues with thermoregulation and cold stress (Morrison et al., 1970; Holmes et al., 1978; Muller et al., 1996; Fisher et al., 2003). The cows on the wet surface spent less time lying with the front legs in a tucked position, which Tucker et al. (2007) suggested could be an attempt to preserve body temperature. However, neither the ambient temperature nor the surface temperature in the current study were likely cold enough to cause such a change in behavior. Second, wetness may have longer-term effects on hoof health as it has been shown that the hoof absorbs water rapidly, which leads to a decrease in claw hardness and increased risk of lameness (Borderas et al., 2004).

Cows also showed a reduction in lying time and avoided the surface contaminated with manure. It is possible that the difference in preference is partly due to the DM content of the treatments $(44,40$, and $23 \%$ for clean, dirty, and wet, respectively); however, it has also been shown that cattle avoid forage contaminated with manure (Forbes and Hodgson, 1985; Bao et al., 1998) and also avoid drinking water that has been contaminated with manure (Willms et al., 2002). Even though research has shown that cattle seem to avoid contamination of their bodies with manure (Whistance et al., 2011), this is to our knowledge the first study to demonstrate that, if possible, dairy cattle will actively avoid lying down on surfaces contaminated with manure. In addition, some evidence indicated that cows avoided urinating on the clean and dry surface. Cattle avoid manure, but preferred it to the wet treatment in the pairwise comparison. This finding is consistent with the behavioral changes in the no-choice situation: cows spent less time lying on the manure-laden surface compared with the clean and dry option, but differences in this behavior were not as drastic as the effect of the wet surface. 
Finally, surfaces contaminated with manure influence the cleanliness and hygiene of cows, as shown in this study. Moisture and manure in the environment are likely to lead to increased risk of exposure to pathogens that will cause mastitis (Schreiner and Ruegg, 2002). Furthermore, poor hygiene has been shown to be associated with higher SCC and risk of subclinical mastitis in dairy cows (Barkema et al., 1999; Schreiner and Ruegg, 2003; Reneau et al., 2005; Dohmen et al., 2010).

\section{CONCLUSIONS}

Dairy cattle exposed to a wet surface spent less time lying on this surface and instead spent more time resting when on pasture, a time when ideally they should be feeding. Cows on the wet surface also spent less time lying in a lateral position and with their heads supported, indicating reduced cow comfort on this surface. This is the first study to demonstrate that dairy cattle spend less time lying and avoid surfaces contaminated with manure. When given a free choice, cows showed a clear preference for a dry, clean surface over wet and dirty surfaces. The aversion against the wet surface was particularly marked.

\section{ACKNOWLEDGMENTS}

Technical assistance from AgResearch staff and people associated with AgResearch at the time is greatly appreciated: Ari Bright, Tania Blackmore, Stephanie Delaney, Suzanne Dowling, Stu Eaton, Rose Greenfield, Gemma Lowe, Simon Mc Creesh, Ian Moon, Ross Finlay, Jeremy Powell, Trevor Watson, and Claire Vedrine. We also thank the staff at the Ruakura Research farm, in particular the farm manager Tim Hale. The project was funded by New Zealand dairy farmers through DairyNZ (Hamilton, New Zealand) and by the Ministry of Business, Innovation and Employment (Wellington, New Zealand, contract no. C10X0813).

\section{REFERENCES}

Bao, J., P. S. Giller, and G. Stakelum. 1998. Selective grazing by dairy cows in the presence of dung and defoliation of tall grass dung patches. Anim. Sci. 66:65-73. https://doi.org/10.1017/ S1357729800008845.

Barkema, H. W., J. D. Van der Ploeg, Y. H. Schukken, T. J. G. M Lam, G. Benedictus, and A. Brand. 1999. Management style and its association with bulk milk somatic cell count and incidence rate of clinical mastitis. J. Dairy Sci. 82:1655-1663. https://doi.org/10 .3168/jds.S0022-0302(99)75394-4.

Borderas, T. F., B. Pawluczuk, A. M. de Passillé, and J. Rushen. 2004 Claw hardness of dairy cows: Relationship to water content and claw lesions. J. Dairy Sci. 87:2085-2093. https://doi.org/10.3168/ jds.S0022-0302(04)70026-0.

Chen, J. M., C. L. Stull, D. N. Ledgerwood, and C. B. Tucker. 2017. Muddy conditions reduce hygiene and lying time in dairy cattle and increase time spent on concrete. J. Dairy Sci. 100:2090-2103. https://doi.org/10.3168/jds.2016-11972.

Cooper, M. D., D. R. Arney, and C. J. C. Phillips. 2007. Two- or fourhour lying deprivation on the behavior of lactating dairy cows. J. Dairy Sci. 90:1149-1158. https://doi.org/10.3168/jds.S0022 -0302(07)71601-6.

Degen, A. A., and B. A. Young. 1993. Rate of metabolic heat production and rectal temperature of steers exposed to simulated mud and rain conditions. Can. J. Anim. Sci. 73:207-210. https://doi .org/10.4141/cjas93-021.

Dohmen, W., F. Neijenhuis, and H. Hogeveen. 2010. Relationship between udder health and hygiene on farms with an automatic milking system. J. Dairy Sci. 93:4019-4033. https://doi.org/10.3168/ jds.2009-3028.

Fisher, A. D., M. Stewart, G. A. Verkerk, C. J. Morrow, and L. R. Matthews. 2003. The effects of surface type on lying behaviour and stress responses of dairy cows during periodic weather-induced removal from pasture. Appl. Anim. Behav. Sci. 81:1-11. https:// doi.org/10.1016/S0168-1591(02)00240-X.

Fisher, A. D., G. A. Verkerk, C. J. Morrow, and L. R. Matthews. 2002 The effects of feed restriction and lying deprivation on pituitaryadrenal axis regulation in lactating cows. Livest. Prod. Sci. 73:255263. https://doi.org/10.1016/S0301-6226(01)00246-9.

Forbes, T. D. A., and J. Hodgson. 1985. The reaction of grazing sheep and cattle to the presence of dung from the same or other species. Grass Forage Sci. 40:177-182. https://doi.org/10.1111/j.1365-2494 .1985.tb01735.x.

Fregonesi, J. A., and D. J. Leaver. 2001. Behaviour, performance and health indicators of welfare for dairy cows housed in strawyard or cubicle systems. Livest. Prod. Sci. 68:205-216. https://doi.org/10 .1016/S0301-6226(00)00234-7.

Fregonesi, J. A., D. M. Veira, M. A. G. von Keyserlingk, and D. M. Weary. 2007. Effects of bedding quality on lying behavior of dairy cows. J. Dairy Sci. 90:5468-5472. https://doi.org/10.3168/jds.2007 -0494 .

Haley, D. B., J. Rushen, and A. M. de Passillé. 2000. Behavioura indicators of cow comfort: Activity and resting behaviour of dairy cows in two types of housing. Can. J. Anim. Sci. 80:257-263. https: //doi.org/10.4141/A99-084

Hernandez-Mendo, O., M. A. G. von Keyserlingk, D. M. Veira, and D. M. Weary. 2007. Effects of pasture on lameness in dairy cows. J. Dairy Sci. 90:1209-1214. https://doi.org/10.3168/jds.S0022 -0302(07)71608-9.

Holmes, C. W., R. Christensen, N. A. McLean, and J. Lockyer. 1978 Effects of winter weather on the growth rate and heat production of dairy cattle. N. Z. J. Agric. Res. 21:549-556. https://doi.org/10 $.1080 / 00288233.1978 .10427449$.

Jubb, T. F., and J. Malmo. 1991. Lesions causing lameness requiring veterinary treatment in pasture-fed dairy cows in East Gippsland Aust. Vet. J. 68:21-24. https://doi.org/10.1111/j.1751-0813.1991 .tb09836.x.

Krohn, C. C., and L. Munksgaard. 1993. Behaviour of dairy cows kept in extensive (loose housing/pasture) or intensive (tie stall) environments. II. Lying and lying-down behaviour. Appl. Anim. Behav. Sci. 37:1-16. https://doi.org/10.1016/0168-1591(93)90066-X.

Loberg, J., E. Telezhenko, C. Bergsten, and L. Lidfors. 2004. Behaviour and claw health in tied dairy cows with varying access to exercise in an outdoor paddock. Appl. Anim. Behav. Sci. 89:1-16 https://doi.org/10.1016/j.applanim.2004.04.009.

Morrison, S. R., R. L. Givens, W. N. Garrett, and T. E. Bond. 1970 Effects of mud-wind-rain on beef cattle performance in feed lot. Calif. Agric. 24:6-7.

Muller, C. J. C., J. A. Botha, and W. A. Smith. 1996. Effect of confinement area on production, physiological parameters and behaviour of Friesian cows during winter in a temperate climate. S. Afr J. Anim. Sci. 26:1-5.

Munksgaard, L., K. L. Ingvartsen, L. J. Pedersen, and V. K. M. Nielsen. 1999. Deprivation of lying down affects behaviour and pituitaryadrenal axis responses in young bulls. Acta Agric. Scand. A Anim. Sci. 49:172-178. https://doi.org/10.1080/090647099424088. 
Munksgaard, L., and H. B. Simonsen. 1996. Behavioural and pituitary adrenal-axis responses of dairy cows to social isolation and deprivation of lying down. J. Anim. Sci. 74:769-778. https://doi.org/10 $.2527 / 1996.744769 x$.

Rajapaksha, E., and C. B. Tucker. 2014. How do cattle respond to sloped floors? An Investigation using behavior and electromyograms. J. Dairy Sci. 97:2808-2815. https://doi.org/10.3168/jds .2013-7435.

Reich, L. J., D. M. Weary, D. M. Veira, and M. A. G. von Keyserlingk. 2010. Effects of sawdust bedding dry matter on lying behavior of dairy cows: A dose-dependent response. J. Dairy Sci. 93:15611565. https://doi.org/10.3168/jds.2009-2713.

Reneau, J. K., A. J. Seykora, B. H. Heins, M. I. Endres, R. J. Farnsworth, and R. F. Bey. 2005. Association between hygiene scores and somatic cell scores in dairy cattle. J. Am. Vet. Med. Assoc. 227:1297-1301. https://doi.org/10.2460/javma.2005.227.1297.

Schreiner, D. A., and P. L. Ruegg. 2002. Effects of tail docking on milk quality and cow cleanliness. J. Dairy Sci. 85:2503-2511. https:// doi.org/10.3168/jds.S0022-0302(02)74333-6.

Schreiner, D. A., and P. L. Ruegg. 2003. Relationship between udder and leg hygiene scores and subclinical mastitis. J. Dairy Sci. 86:3460-3465. https://doi.org/10.3168/jds.S0022-0302(03)73950 -2 .

Schütz, K. E., K. V. Clark, N. R. Cox, L. R. Matthews, and C. B. Tucker. 2010. Responses to short-term exposure to simulated rain and wind by dairy cattle: time budgets, shelter use, body temperature and feed intake. Anim. Welf. 19:375-383.

Schütz, K. E., and N. R. Cox. 2014. Effects of short-term repeated exposure to different flooring surfaces on the behavior and physiology of dairy cattle. J. Dairy Sci. 97:2753-2762. https://doi.org/10 $.3168 /$ jds.2013-7310.

Schütz, K. E., F. Huddart, M. A. Sutherland, M. Stewart, and N. R. Cox. 2015. Effects of space allowance on the behavior and physiol- ogy of cattle temporarily managed on rubber mats. J. Dairy Sci 98:6226-6235. https://doi.org/10.3168/jds.2015-9593.

Ternman, E., M. Pastell, S. Agenäs, C. Strasser, C. Winckler, P. Peetz Nielsen, and L. Hänninen. 2014. Agreement between different sleep states and behaviour indicators in dairy cows. Appl. Anim. Behav. Sci. 160:12-18. https://doi.org/10.1016/j.applanim.2014.08.014.

Thomsen, P. T., L. Munksgaard, and F. A. Tøgersen. 2008. Evaluation of a lameness scoring system for dairy cows. J. Dairy Sci. 91:119-126. https://doi.org/10.3168/jds.2007-0496.

Tucker, C. B., L. Munksgaard, E. M. Mintline, and M. B. Jensen. 2018. Use of a pneumatic push gate to measure dairy cattle motivation to lie down in a deep-bedded area. Appl. Anim. Behav. Sci. 201:15-24. https://doi.org/10.1016/j.applanim.2017.12.018.

Tucker, C. B., A. R. Rogers, G. A. Verkerk, P. E. Kendall, J. R Webster, and L. R. Matthews. 2007. Effects of shelter and body condition on the behaviour and physiology of dairy cattle in winter. Appl. Anim. Behav. Sci. 105:1-13. https://doi.org/10.1016/j applanim.2006.06.009.

Tucker, C. B., D. M. Weary, and D. Fraser. 2003. Effects of three types of free-stall surfaces on preferences and stall usage by dairy cows. J. Dairy Sci. 86:521-529. https://doi.org/10.3168/jds.S0022 -0302(03)73630-3.

Whistance, L. K., L. A. Sinclair, D. R. Arney, and C. J. C. Phillips 2011. Eliminative behaviour of dairy cows at pasture. Appl. Anim. Behav. Sci. 130:73-80. https://doi.org/10.1016/j.applanim.2010.12 .011 .

Williams, L. A., G. J. Rowlands, and A. M. Russell. 1986. Effect of wet weather on lameness in dairy cattle. Vet. Rec. 118:259-261. https: //doi.org/10.1136/vr.118.10.259.

Willms, W. D., O. R. Kenzie, T. A. McAllister, D. Colwell, D. Veira, J. F. Wilmshurst, T. Entz, and M. E. Olson. 2002. Effects of water quality on cattle performance. J. Range Manage. 55:452-460. https://doi.org/10.2307/4003222 